\title{
Label-Free Detection and Self-Aggregation of Amyloid $\beta$ - Peptides Based on Plasmonic Effects Induced by Ag Nanoparticles: Implications in Alzheimer's Disease Diagnosis
}

\author{
Adianez Garcia-Leis and Santiago Sanchez-Cortes*
}

Instituto de Estructura de la Materia, IEM-CSIC, Serrano 121, 28006-Madrid, Spain. 


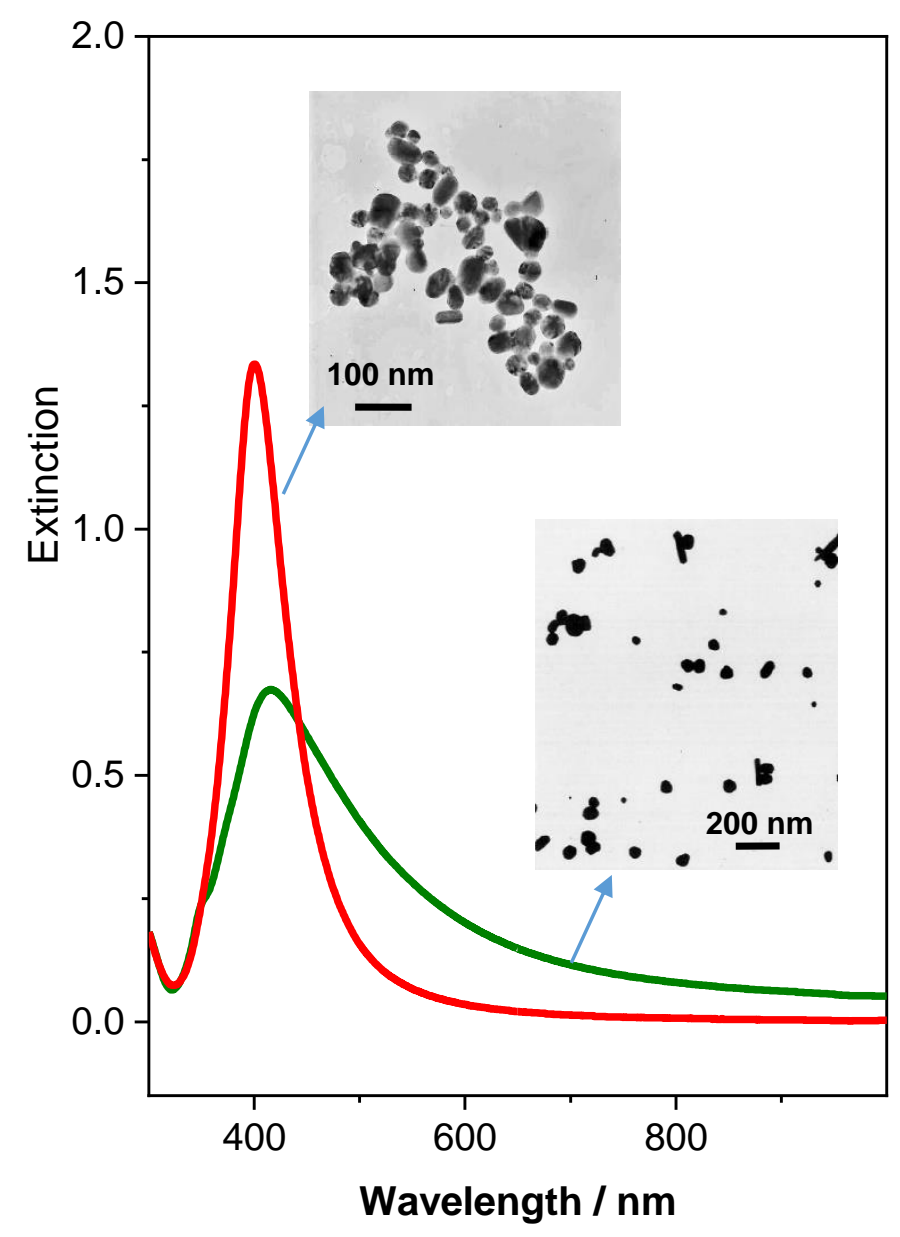

Figure S1. Extinction spectra of the different AgNPs used in this work: Citrate AgNPs (green line) and Hydroxylamine AgNPs (red line) and corresponding TEM images of the resulting AgNPs. 


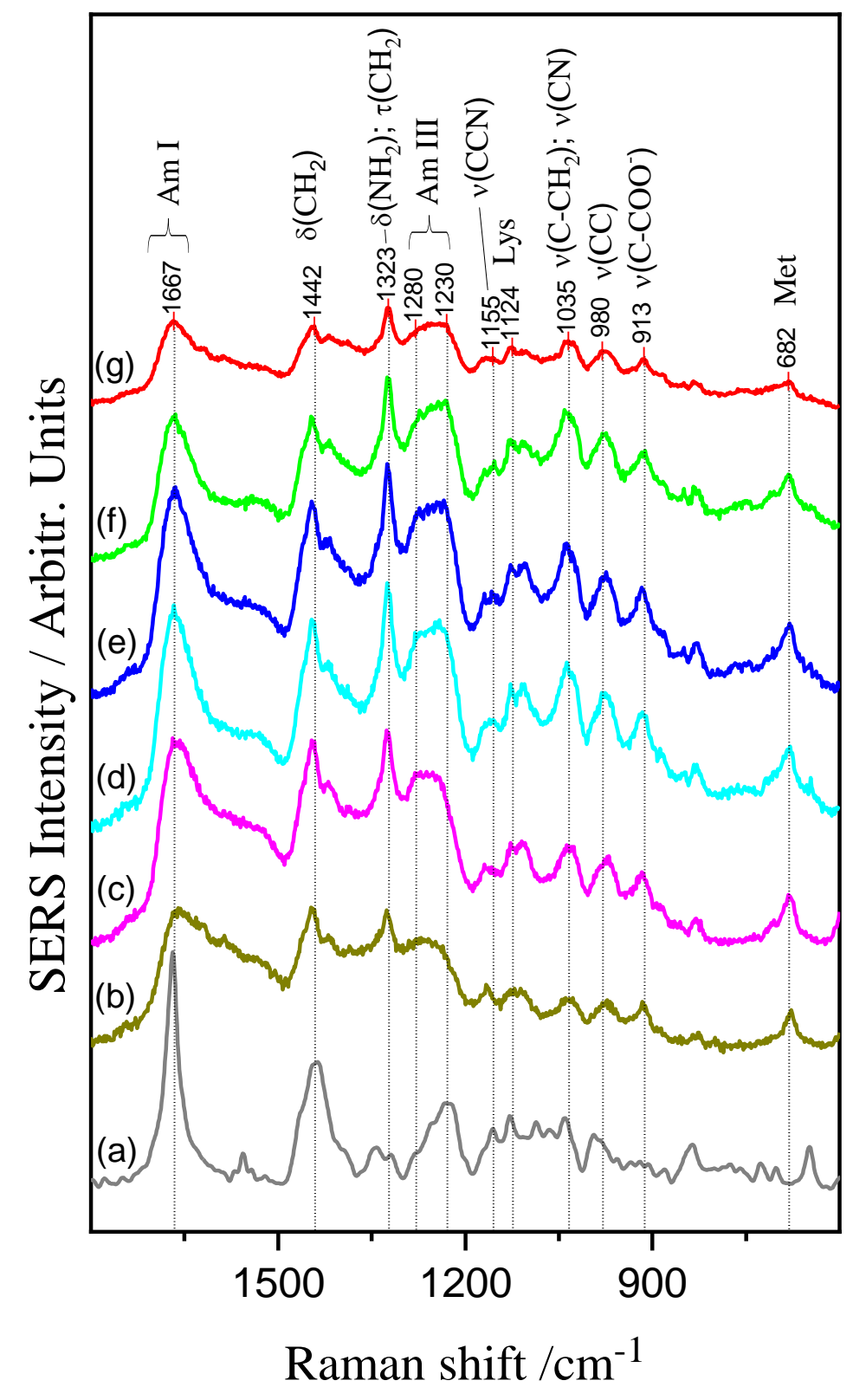

Figure S2. Raman spectrum of solid A $\beta(25-35)$ peptide (a) and SERS spectra registered on AgNPs at the following concentrations of the peptide: 0.5 (b); 1 (c); 3 (d); 5 (e); 8(f) and $10 \mu \mathrm{M}(\mathrm{g})$. Excitation at $532 \mathrm{~nm}$. 

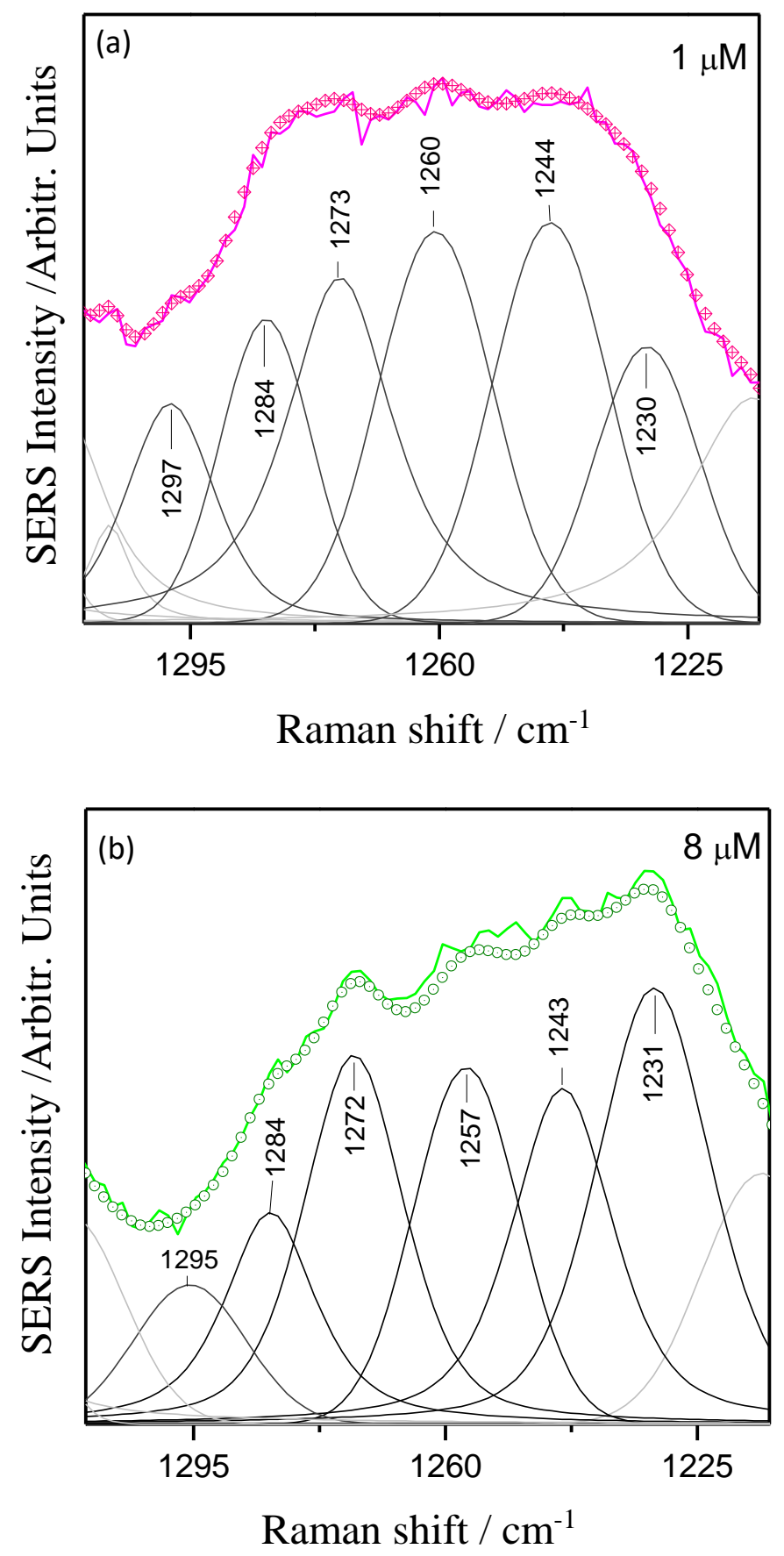

Figure S3. Deconvolution of Amide III band of SERS of Raman spectrum of $A \beta(25-$ 35) peptide at concentrations 1 (a) and $8 \mu \mathrm{M}(\mathrm{g})$. Excitation at $532 \mathrm{~nm}$. 